\title{
Quality of Intra-Hospital Nutritional Counseling in Patients with STEMI in the Public and Private Health Networks of Sergipe: The VICTIM Register
}

\author{
Ticiane Clair Remacre Munareto Lima, ${ }^{1 \oplus}$ Danielle Góes da Silva, ${ }^{\circledR \oplus}$ Ikaro Daniel de Carvalho Barreto, ${ }^{3 \oplus}$ Jussiely

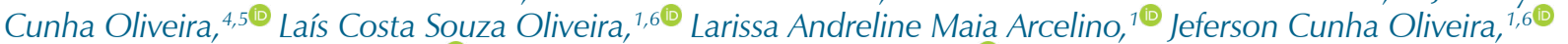 \\ Antônio Carlos Sobral Sousa, 1,7,8®0 José Augusto Soares Barreto Filho ${ }^{1,7,8(\mathbb{0}}$ \\ Universidade Federal de Sergipe - Programa de Pós-Graduação em Ciências da Saúde, ${ }^{1}$ São Cristóvão, SE - Brazil \\ Universidade Federal de Sergipe - Departamento de Nutrição, ${ }^{2}$ São Cristóvão, SE - Brazil \\ Universidade Federal Rural de Pernambuco - Núcleo de Pós-graduação em Biometria e Estatística Aplicada, ${ }^{3}$ Recife, PE - Brazil \\ Universidade Federal de Sergipe - Programa de Pós-Graduação em Enfermagem, ${ }^{4}$ São Cristóvão, SE - Brazil \\ Universidade Tiradentes, ${ }^{5}$ Aracaju, SE - Brazil \\ Hospital Primavera, ${ }^{6}$ Aracaju, SE - Brazil \\ Universidade Federal de Sergipe - Departamento de Medicina, ${ }^{7}$ São Cristóvão, SE - Brazil \\ Fundação São Lucas - Centro de Ensino e Pesquisa, ${ }^{8}$ Aracaju, SE - Brazil
}

\begin{abstract}
Background: Having appropriate dietary habits is part of the recommendations after ST-Elevation Myocardial Infarction (STEMI), however, the quality of intra-hospital nutritional counseling in the different health services has been minimally explored.
\end{abstract}

Objective: To evaluate the quality of intra-hospital nutritional counseling among patients with STEMI in the public and private health systems in Sergipe.

Methods: A cross-sectional, with data from the Via Crucis for the Treatment of Myocardial Infarction (VICTIM) Register, conducted from April to November of 2017, with individuals aged $\geq 18$ years diagnosed with STEMI, in one public health service hospital and three private hospitals. The occurrence and quality of nutritional counseling were analyzed based on current guidelines and the administration of questionnaires. A significance level of 0.05 was adopted.

Results: A total of 188 patients were analyzed; $80.3 \%$ were from the public health service facility. Among the interviewees, $\mathbf{5 7 . 6 \%}$ of the public health service, and $\mathbf{7 0 . 3} \%$ of the private hospital patients received intra-hospital nutritional counseling $(p=0.191)$. The documentation of this practice, in medical records, was lower in the public service $(2.6 \%$ vs. $37.8 \%$, p $<0.001$ ). A predominance of restrictive orientations was found in the public and private sectors, mainly regarding salt and fat, $52.3 \%$ and $70.3 \%$ respectively $(p=0.064)$. Patients from the private service were more counseling to introduce of cardioprotective foods, mainly fruit, vegetable/legume consumption $(48.6 \% \mathrm{vs} .13 .2 \%, \mathrm{p}<0.001)$. Among those who received counseling, nutritional knowledge was higher in the private sector $(68.2 \% \mathrm{vs} .26 .3 \%, \mathrm{p}<0.001)$.

Conclusion: The intra-hospital nutritional counseling provided to patients with STEMI, in Sergipe, still presents poor quality in both services, especially in the public health system. (Arq Bras Cardiol. 2019; 113(2):260-269)

Keywords: ST Elevation Myocardial Infarction; Health Education/methods; Healthy Diet; Risk Reduction Behavior; Healthcare Disparities; Nutritional Support; Hospitals,Public; Hospitals, Private.

\section{Introduction}

Cardiovascular diseases (CVD) are the leading causes of death in the world, with a higher prevalence in lowand middle-income countries. They are responsible for approximately $30 \%$ of deaths in Brazil annually, and the ischemic

\footnotetext{
Mailing Address: Ticiane Clair Remacre Munareto Lima •

Universidade Federal de Sergipe - Programa de Pós-Graduação em Ciências da Saúde

Rua Cláudio Batista, s/n. Postal Code 49060-108, Cidade Nova, Aracaju, Sergipe - Brazil

E-mail: ticiane.nutricionista@gmail.com

Manuscript received June 25, 2018, revised manuscript October 08, 2018, accepted October 24, 2018
}

DOI: $10.5935 / a b c .20190124$ heart diseases are the main causes of this high mortality, with an emphasis on acute myocardial infarction (AMI), due to its magnitude and the severity of its clinical prognosis. ${ }^{1-5}$

After the acute coronary event, actions are necessary for secondary prevention of the disease, which should consist of adherence to prescribed medication therapy and lifestyle changes, with an emphasis on the practice of programmed physical activity, adoption of healthy eating habits, and smoking cessation. . $^{6}$

Changes in dietary patterns were highlighted in the prevention and treatment of CVD in epidemiological studies. These studies reinforced that a free of trans-fatty acid diet, restriction of saturated fat, salt, alcoholic beverages, and increase in dietary fibre with a predominance of whole grains, fruits, vegetables and legumes, brought cardioprotective 
benefits associated with the reduction of important cardiovascular outcomes. ${ }^{11-15}$

Quality indicators and guidelines related to AMI recommend that these dietary changes must be guided by health professionals, even still during the in-hospital period. This contributes to the empowerment of the individual, and provides greater awareness of his role in relation to his own health, in addition to guiding his food choices, and increasing his nutritional knowledge. ${ }^{7,9,16-20}$

Previous studies demonstrated the existence of disparities in the quality of care between public and private health services, related to the time to perform examinations, and the use of cardiovascular medications. ${ }^{21,22}$ This finding is concerning because approximately $72 \%$ of the Brazilian population is exclusively dependent on the Unified Health System (SUS). ${ }^{23}$ However, the type of care provided by health professionals regarding nutritional counseling is poorly explored, and possible differences in the quality of this orientation in the in-hospital environment between the two health services are not yet known.

Thus, the present study aims to evaluate the quality of nutritional counseling received in the in-hospital environment in patients with ST-segment elevation myocardial infarction (STEMI) receiving care in the public and private health services in Sergipe.

\section{Methods}

This was a cross-sectional, quantitative study which used data from the Via Crucis for the Treatment of Myocardial Infarction (VICTIM) Register, which aims to evaluate the quality of care provided to patients with STEMI in the public and private health systems in Sergipe.

Data collection occurred from April to November of 2017, in the only four hospitals in the state with the capacity to perform primary angioplasty, all located in the Aracaju capital, one with SUS coverage and three with private coverage.

Patients of both sexes, older than 18 years of age, with a STEMI diagnosis confirmed by electrocardiogram were included, according to the defining criteria proposed by the Brazilian Society of Cardiology. ${ }^{24}$ Individuals excluded were those who: died prior to concluding all stages of the study; did not meet the Via Crucis criteria, that is, those patients who did not travel the course from the beginning of the symptoms until arrival at the hospital with the ability to perform angioplasty, because they were already in the hospital when they experienced the STEMI; did not agree to participate in some stage of the research; those whose acute STEMI event was characterized as reinfarction (occurred within 28 days of the primary infarction); presented a change of diagnosis during hospitalization; were funded by private health insurance in a philanthropic hospital; and, were unable to be contacted by telephone within seven days after hospital discharge.

This research was approved by the Research Ethics Committee of the Federal University of Sergipe (UFS), under opinion $\mathrm{n}$ - 2,099,430. All procedures involved in this study are in accordance with the Declaration of Helsinki of 1975, updated in 2013. All patients signed the Terms of Free and Informed Consent form.
The data collection was performed in two stages: in the hospital environment and after discharge by telephone interview. In the hospital, a study instrument was used, the Case Report Form (CRF), which is composed of sociodemographic variables, previous pathological history, cardiovascular risk factors, physical examination on admission, and nutritional counseling recorded in the clinical patient records.

The second stage of the research occurred via telephone contact with the patients, within seven days after hospital discharge; this interval was determined after the pilot study and pondered the need for an immediate interview with them. At that time, the occurrence of nutritional counseling during the hospital period was evaluated, even though it was not recorded in the patient records by the health professional. In addition, the National Health Interview Survey Cancer Epidemiology was administered, a nutritional knowledge scale adapted for the present study. ${ }^{25}$

At this moment in time, the quality of in-hospital nutritional counseling was also assessed, using a closed-ended questionnaire based on the items proposed in the guidelines. ${ }^{9,18,26,27}$ The categories of responses were "oriented", "not oriented", and "do not know". The presence or absence of a recommendation on physical activity after AMI, as established in the aforementioned guidelines, was also observed.

The nutritional status of the patients was obtained using the Body Mass Index (BMI), calculated by means of the body mass (weight) $(\mathrm{kg}$ ) divided by the square of the body height $\left(\mathrm{m}^{2}\right)$, and classified according to the cutoff points proposed by the $\mathrm{WHO}^{28}$

\section{Statistical analysis}

The Kolmogorov-Smirnov test was applied to evaluate the assumption of sample normality. Continuous variables that presented a normal distribution were described using mean and standard deviation; those that did not present a normal distribution were represented using median and interquartile range. The Student's t-test or the Mann-Whitney test was used for the independent groups, based on the normality standard of the sample. Absolute frequency and percentage were used for the categorical variables. To compare characteristics of the categorical variables between the two groups, the chi-square test or the Fisher's exact test were used, when appropriate. The significance level of $5 \%$ was used as a reference. A sampling plan was established in order to detect differences in the magnitude of mean between public and private health service samples. A significance of $1 \%$ and a power of $90 \%$ were established for comparisons between these two groups. Non-parametric tests were also used, and in order to obtain the same test power, a correction of 0.86429 was established..$^{29}$ In the data collection, the final sample remained similar in proportion to what was initially established $\left(X^{2}=0.01, p=0.912\right)$, preserving the initial conditions of power, level of significance, and design, as well as preserving the initial intention for detecting differences of mean magnitude between the two groups (public vs. private). The SPSS for Windows program, Version 17, was used for statistical analysis. 


\section{Results}

A total of 188 patients was analyzed, $80.3 \%$ received care in the public service and $19.7 \%$ in the private health service, in the state of Sergipe.

\section{Demographic characteristics}

The patients who received care in the public service the Unified Health System (Sistema Único de Saúde [SUS]) showed a predominance of non-white ethnicity, lower social class, with prevalence of the two lowest socioeconomic classes, and lower level of education (Table 1).

\section{Clinical characteristics}

Both groups, who received care in the two health services showed similar clinical characteristics, except for the smoking risk factor, in which the patients who received care in the SUS facility presented a significantly higher smoking rate (35.1\% vs. $13.5 \%, p=0.010)$. With regards to the previous history of $\mathrm{AMI}$, patients who received care in the private health service presented a higher prevalence (Table 2).

\section{Intra-hospital nutritional counseling}

Based on the total sample, telephone contact with the patients occurred within five days (IIQ 3-6 days); when analyzed, for the patients from SUS, the median was 4 days (IIQ 4-6 days), and for those in the private service, it was five days (IIQ 3-6 days).
Although most patients reported having received in-hospital nutritional counseling, this was documented in the records of only $9.6 \%$ of the patients. Overall, according to the patient reports, the physician was the health professional who provided the most information about diet (85.8\%) (Table 3).

Compared with the SUS, a larger contingent of patients from the private service reported having received verbal and written nutritional counseling. Regarding the professional who provided this information, the nutritionist was mentioned significantly more by the private service patients (50\% vs. $11.5 \%$, $\mathrm{p}<0.001)$. In the private service, more documentation of nutritional orientation occurred in the patient records $(37.8 \%$ vs $2.6 \%, \mathrm{p}<0.001$ ), and more patients had nutritional counseling prior to hospitalization $(64.9 \%$ vs. $33.8 \%$, p < 0.001) (Table 3).

Types of self-reported intra-hospital nutritional counseling

When compared to the SUS, more patients from the private service mentioned receiving guidelines on restriction of: sausages $(p<0.001)$; refined carbohydrates $(p=0.008)$; alcoholic beverages $(p=0.002)$. More also mentioned the introduction of: skimmed milk and dairy products $(p=0.01)$; grilled and steamed cooking preparations ( $p<0.001)$; fish $(p<0.001)$; extra virgin olive oil ( $p=0.035)$; fruits and vegetables $(p<0.001)$; and, whole grains and fiber $(p=0.001)$ (Figure 1$)$.

In both health services, there was a predominance of restrictive of salty and salty foods, and of fats and fries with a prevalence of $52.3 \%$ and $70.3 \%$ in public and private, respectively $(p=0.064)$ (Figure 1$)$.

Table 1 - Sociodemographic characteristics of patients with STEMI receiving care at hospitals in Sergipe, based on the type of service (Public vs. Private)

\begin{tabular}{|c|c|c|c|c|}
\hline Variables & Total (188) & Public (151) & Private (37) & $p$ value \\
\hline Age, years (Mean $\pm S D$ ) & $61.5 \pm 11.7$ & $61.3 \pm 11.7$ & $62.5 \pm 11.7$ & $0.798^{\top}$ \\
\hline Male sex, n (\%) & $126(67.0)$ & $98(64.9)$ & $28(75.7)$ & $0.246^{Q}$ \\
\hline \multicolumn{5}{|l|}{ Ethnicity, n (\%) } \\
\hline White & $70(37.2)$ & $48(31.8)$ & $22(59.5)$ & $0.002^{Q}$ \\
\hline Nonwhite & $118(62.8)$ & $103(68.2)$ & $15(40.5)$ & \\
\hline \multicolumn{5}{|l|}{ Social class, $\mathrm{n}(\%)^{*}$} \\
\hline$A / B$ & $11(6.0)$ & $2(1.4)$ & $9(25.7)$ & $<0.001^{Q}$ \\
\hline C & $30(16.5)$ & $15(10.2)$ & $15(42.9)$ & \\
\hline $\mathrm{D} / \mathrm{E}$ & $141(77.5)$ & $130(88.4)$ & $11(31.4)$ & \\
\hline \multicolumn{5}{|l|}{ Level of education, $n(\%)$} \\
\hline Elementary school or less & $130(69.1)$ & $122(80.8)$ & $8(21.6)$ & $<0.001^{Q}$ \\
\hline High school & $38(20.2)$ & $20(13.2)$ & $18(48.6)$ & \\
\hline Higher education or graduation & $20(10.6)$ & $9(6.0)$ & $11(29.7)$ & \\
\hline \multicolumn{5}{|l|}{ Marital status, $\mathrm{n}(\%)$} \\
\hline Single & $12(6.4)$ & $10(6.6)$ & $2(5.4)$ & $1.000^{Q}$ \\
\hline Married/Living with a partner & $129(68.6)$ & $103(68.2)$ & $26(70.3)$ & \\
\hline Divorced/Widower & $47(25.0)$ & $38(25.2)$ & $9(24.3)$ & \\
\hline
\end{tabular}

SD: standard deviation; (*) Social classification (IBGE, 2010) according to family income: A-Above 20 minimum wages, B- 10 to 20 minimum wages, C- 4 to 10 minimum wages, D- 2 to 4 minimum wages, E- Up to 2 minimum wages; T-Test T for independent samples; Q- Chi-square test. 


\section{Original Article}

Table 2 - Clinical characteristics of the patients with STEMI receiving care at hospitals in Sergipe, based on the type of service (Public vs. Private)

\begin{tabular}{|c|c|c|c|c|}
\hline Variables & Total (188) & Public (151) & Private (37) & p value \\
\hline $\mathrm{SBP}, \mathrm{mm} \mathrm{Hg}^{*}$ & $140(128-160)$ & $140(128-160)$ & $140(123-160)$ & $0.909^{\#}$ \\
\hline DBP, mm Hg† & $86(80-92)$ & $84(79-92)$ & $90(79-96)$ & $0.190^{\#}$ \\
\hline $\mathrm{HR}$, beats/min $\ddagger$ & $85(72-98)$ & $85(72-97)$ & $80(68-100)$ & $0.849^{\#}$ \\
\hline GRACE Score & $136(119-157)$ & $135(119-155)$ & $142(117-168)$ & $0.228^{\#}$ \\
\hline \multicolumn{5}{|l|}{ GRACE Score, $n(\%)$} \\
\hline$<140$ (low risk) & $98(55.1)$ & $81(57.0)$ & $17(47.2)$ & $0.349^{* \prime}$ \\
\hline$\geq 140$ (high risk) & $80(44.9)$ & $61(43.0)$ & $19(52.8)$ & \\
\hline \multicolumn{5}{|l|}{ Killip, $n(\%)$} \\
\hline । & $169(90.4)$ & $139(92.1)$ & $30(83.3)$ & $0.108^{\prime \prime}$ \\
\hline$\|$ & $12(6.4)$ & $9(6.0)$ & $3(8.3)$ & \\
\hline III & $5(2.7)$ & $3(2.0)$ & $2(5.6)$ & \\
\hline IV & $1(0.5)$ & $0(0.0)$ & $1(2.8)$ & \\
\hline \multicolumn{5}{|l|}{ Cardiovascular risk factors, $\mathrm{n}(\%)$} \\
\hline Family history of early CAD § & $70(37.2)$ & $53(35.1)$ & $17(45.9)$ & $0.256^{* \prime}$ \\
\hline Systemic Arterial Hypertension & $129(68.6)$ & $103(68.2)$ & $26(70.3)$ & $1.000^{\prime \prime}$ \\
\hline Dyslipidemia & $76(40.4)$ & $57(37.7)$ & $19(51.4)$ & $0.139 "$ \\
\hline Diabetes Mellitus & $60(31.9)$ & $48(31.8)$ & $12(32.4)$ & $1.000^{* \prime}$ \\
\hline Smoking & $58(30.9)$ & $53(35.1)$ & $5(13.5)$ & $0.010^{* \prime}$ \\
\hline \multicolumn{5}{|l|}{ Clinical history, $\mathrm{n}(\%)$} \\
\hline Previous $\mathrm{PVD}^{\prime \prime}$ & $20(10.6)$ & $17(11.3)$ & $3(8.1)$ & $0.769^{\dagger+}$ \\
\hline Previous myocardial infarction & $12(6.4)$ & $6(4.0)$ & $6(16.2)$ & $0.015^{\prime \prime}$ \\
\hline Cardiac insufficiency & $7(3.7)$ & $6(4.0)$ & $1(2.7)$ & $1.000^{+t}$ \\
\hline Previous PCI & $10(5.3)$ & $5(3.3)$ & $5(13.5)$ & $0.027^{\prime \prime}$ \\
\hline \multicolumn{5}{|l|}{ Nutritional Diagnosis, $\mathrm{n}(\%)$} \\
\hline Low weight & $3(1.6)$ & $2(1.5)$ & $1(2.9)$ & $0.171^{* \prime}$ \\
\hline Eutrophic & $64(37.6)$ & $53(39.3)$ & $11(31.4)$ & \\
\hline Overweight & $70(41.2)$ & $58(43.0)$ & $12(34.3)$ & \\
\hline Obesity & $33(19.4)$ & $22(16.3)$ & $11(31.4)$ & \\
\hline
\end{tabular}

$\left(^{*}\right)$ SBP: systolic blood pressure; (†) DBP: diastolic blood pressure; (†) HR: heart rate; (§) CAD: coronary artery disease; (I/) PVD: peripheral vascular disease; (T) PCl: percutaneous coronary intervention; (\#) Mann-Whitney test; $\left.{ }^{* *}\right)$ Chi-square test; (†t) Fisher's exact test.

In both public and private services, the most prevalent guidelines had restrictive characteristics. The most prevalent were salt and salty food restriction, and fat and fried food limitations ( $50.3 \%$ vs. $70.3 \%, \mathrm{p}=0.064$, respectively), as can be seen in Figure 1.

\section{Relationship between self-reported, intra-hospital} nutritional counseling and nutritional knowledge

Among the patients who received counseling, the nutritional knowledge was higher in the private service when compared to the SUS patients. However, among the non-counselled patients, no differences were observed in the level of nutritional knowledge between the SUS and private health services (Table 4).

\section{Discussion}

The main finding of this investigation was the underutilization of in-hospital nutritional counseling for patients with STEMI, both in the private service and, especially, in the public service. In the SUS hospital, documentation of nutritional counseling was practically non-existent in the patient records. This finding is of concern, because the change in dietary habits is a class one recommendation for the post-AMI patient, and if it is encouraged in the in-hospital setting, there is an increase of adherence to this therapy, due the recent coronary event. $., 16,17,19,20,26$

In the ideal setting, nutritional counseling should continue to be offered, even after hospital discharge, because it would enhance the work initiated in that environment. 
Table 3 - Presence of nutritional counseling registered by professionals and self-referenced by patients with STEMI receiving care at hospitals in Sergipe, based on the type of service (Public vs. Private)

\begin{tabular}{|c|c|c|c|c|}
\hline Nutritional counseling & Total (188) & Public (151) & Private (37) & $p$ value \\
\hline Nutritional counseling, self-referenced by patient, $n(\%)^{*}$ & $113(60.1)$ & $87(57.6)$ & $26(70.3)$ & $0.191^{\dagger}$ \\
\hline \multicolumn{5}{|l|}{ Counseling presentation method, $n(\%)^{*}$} \\
\hline Verbal only & $63(55.8)$ & $50(57.5)$ & $13(50.0)$ & $0.288^{\dagger}$ \\
\hline Writing only & $38(44.2)$ & $33(37.9)$ & $5(19.2)$ & $0.064^{\ddagger}$ \\
\hline Verbal + Writing & $12(10.6)$ & $4(4.6)$ & $8(30.8)$ & $<0.001^{\ddagger}$ \\
\hline \multicolumn{5}{|l|}{ Professional that counseled, $\mathrm{n}(\%)^{*}$} \\
\hline Physician & $97(85.8)$ & $77(88.5)$ & $20(76.9)$ & $0.196^{\dagger}$ \\
\hline Nutritionist & $23(20.4)$ & $10(11.5)$ & $13(50.0)$ & $<0.001^{\dagger}$ \\
\hline Others & $3(2.7)$ & $3(3.4)$ & $0(0.0)$ & $1.000^{\ddagger}$ \\
\hline Counseling documented in patient record, $\mathrm{n}(\%)$ & $18(9.6)$ & $4(2.6)$ & $14(37.8)$ & $<0.001^{\ddagger}$ \\
\hline \multicolumn{5}{|c|}{ Professional who registered the counseling in the record, $n(\%)$} \\
\hline Nutritionist & $9(50.0)$ & $0(0)$ & $9(64.3)$ & $0.082^{\ddagger}$ \\
\hline Physician & $9(50.0)$ & $4(100)$ & $5(35.7)$ & \\
\hline Pre-hospitalization counseling, $\mathrm{n}(\%)$ & $75(39.9)$ & $51(33.8)$ & $24(64.9)$ & $0.001^{\dagger}$ \\
\hline
\end{tabular}

(*) Information declared by the patient via telephone call, after discharge from the hospital; (†) Chi-square test; (†) Fisher's exact test.

However, with the current weakening in the structure of counter-referral in the country, it is clear that individuals, who depend exclusively on the SUS, need logistics to be easy in order to attend these sessions. In this context, the existence of adequate in-hospital nutritional counseling could, in theory, partially repair this deficiency. ${ }^{30-32}$

The physician was the professional who acted the most, transferring these guidelines. This fact can be interpreted in some ways: inexistence, or lack of communication between the multidisciplinary team in the institution where the patient was hospitalized; conduct of important lifestyle changes, only at the time of discharge, is routinely performed by the physician.

Current guidelines indicate that nutritional counseling should be performed and encouraged by the entire, specialized, multi-professional team involved in patient care. This team must be composed of a cardiologist, nurse, nutritionist, and other professionals, with the purpose of promoting health education for the patient, and encouraging changes in lifestyle habits. ${ }^{9,16,20,26}$ In more specific situations, the nutritionist can intercede with more individualized guidelines, as she is the most qualified professional for such intervention.

Another important finding is the disparity in the quality of nutritional guidance between public and private health services. The observation of the constituent elements of the guidelines provided reveals that private service users were privileged, especially with the inclusion of foods considered to be cardioprotective. It should be emphasized that this type of guidance is part of the nutritional recommendations

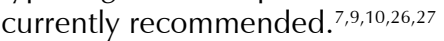

Although private service patients reported receiving more nutritional counseling than public service patients, both received less than $50 \%$ on most of the items analyzed. This low prevalence evidences that the moment of providing information to the patient and/or companion still needs greater attention by health professionals, in both services, as the change in eating habits is related to the cardioprotective effect. ${ }^{7,11,14,15}$

One of the pioneer studies with AMI survivors, conducted by Lorgeril et al., ${ }^{11}$ the Lyon Diet Heart Study, showed that adherence to a diet rich in fruits, vegetables, $\alpha$-linolenic acid, as well as low saturated fats and salt can reduce up to $70 \%$ cardioprotective effect of up to 4 years after the first AMI. More recently, Miller et al. ${ }^{15}$ in the Prospective Urban Rural Epidemiology (PURE) study, demonstrated that the daily consumption of fruits, vegetables, and legumes was inversely associated with the onset of CVD, especially AMI, and, mortality.

The low prevalence of nutritional counseling in the public service may have been affected by the lower concentration of health professionals in this type of service. Although SUS serves the majority of the Brazilian population, the private health network now has three times as many physicians than the public service. ${ }^{33}$ In relation to other professions, in Sergipe, this scenario is not different. Despite the fact that the SUS hospital has a larger number of beds, compared to the private health network, a lower number of nutritionists were observed in this service, in accordance with CFN resolution 600/2018. ${ }^{34}$ This lower number of professionals for a high demand can affect the integral care of the patient, and, consequently, the quality of the nutritional orientation.

The manner of providing this orientation may also have been another point that influenced the low prevalence of nutritional orientation in the SUS, as the majority of respondents of this service reported that it was done verbally. On the other hand, many of those who received the recommendations in written form reported that they were brief, precarious and lacked verbal information, making 


\section{Original Article}

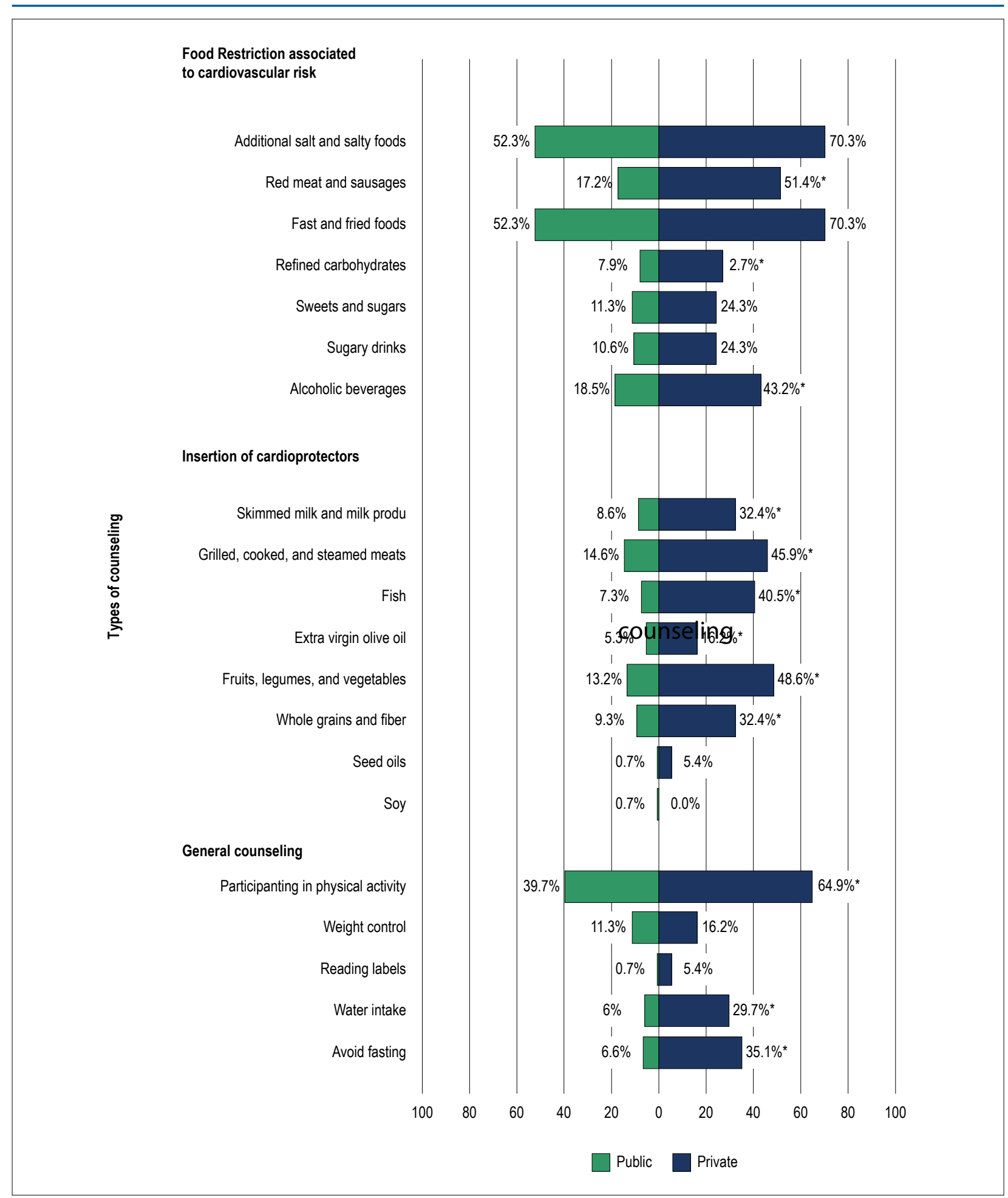

Figure 1 - Types of self-reported intra-hospital nutritional counseling of the patients with STEMI receiving care at hospitals in Sergipe, based on the type of service (Public vs. Private). ( $\left.{ }^{*}\right) p<0,05$; Fisher's exact test

it difficult to understand. Such issues may have made it difficult for the patients to remember the information in the interviews of the present investigation.
In general, predominance of prohibitive guidelines was identified in both services (restriction of salt and/or salty foods, and restriction of fats and fried food). This finding is probably 
Table 4 - Relationship between self-reported in-hospital nutritional counseling and the nutritional knowledge in patients with STEMI receiving care at hospitals in Sergipe, based on the type of service (Public vs. Private)

\begin{tabular}{|c|c|c|c|c|c|c|}
\hline \multirow{2}{*}{ Level of nutritional knowledge } & \multicolumn{2}{|c|}{ Patients counseled (102) } & \multirow[t]{2}{*}{$p$ value } & \multicolumn{2}{|c|}{ Patients not counseled (68) } & \multirow[t]{2}{*}{$p$ value } \\
\hline & Public & Private & & Public & Private & \\
\hline Low, n (\%) & $21(26.3)$ & $1(4.5)$ & $0.001^{*}$ & $14(23.7)$ & $0(0)$ & $0.240^{*}$ \\
\hline Moderate, n (\%) & $38(47.5)$ & $6(27.3)$ & & $23(39.0)$ & $4(44.4)$ & \\
\hline High, $n(\%)$ & $21(26.3)$ & $15(68.2)$ & & $22(37.3)$ & $5(55.6)$ & \\
\hline
\end{tabular}

$\left({ }^{*}\right)$ Chi-square test.

due to the greater practicality of such conduct, and the fact that it was performed, most often, by the physician. It is known that the promotion of the integration and/or replacement of food into the diet requires more in-depth knowledge about the characteristics of the nutrients; this competence is part of the nutritionist's knowledge. ${ }^{35,36}$ This attitude, due to an incomplete nutritional orientation or even the absence of such orientation, does not educate the patient to make healthy food exchanges, which can compromise their nutritional status, by restricting their dietary options.

Furthermore, during the data collection, most of the interviewees did not know what the guidelines meant, they only knew, in general, what they should restrict, without having a specific list with the food.

Similar results were found by Gomes et al., ${ }^{36}$ who verified that the guidelines distributed by the family health professionals to the patients with hypertension and/or diabetes mellitus were simplistic or insufficient. The patients did not have detailed information, with a higher prevalence of prohibitive recommendations, and without taking into account the daily habits of the individuals, and without the benefit of a participatory dialogue with them.

The nutritional knowledge among the patients was higher in private health service. These findings lead to the reflection of the possible positive influence of their level of education in the assimilation of the information provided. We cannot forget, however, that nutritional knowledge is also constructed through information throughout the lifespan, and most patients in the private service already had some kind of nutritional orientation prior to hospitalization. This is a factor that could have influenced these findings. ${ }^{37,38}$

The presence of nutritional counseling facilitates the improvement of nutritional knowledge, and according to the knowledge-attitude-behavior model, there is not a single condition for adherence to healthy eating practices, and may not cause significant positive changes in eating behavior. However, having nutritional knowledge facilitates the beginning of contemplation phases of the individual's behavior change. ${ }^{38,39}$

This worrying scenario of underutilization of in-hospital nutritional orientation can be modified with the adherence of simple behaviors in the work routine of the multi-professional team. Improving the communication of the multi-professional team of care, dedicating more time and attention to the information given to the patient, and jointly dispensing individualized, well-written information to complement the orientation provided is a simple, low-cost alternative that can lead to a positive clinical outcome. ${ }^{36,40}$
In addition, due to the fact that the time of hospital discharge represents a moment of anxiety for the patient and family, this can compromise the assimilation of information. Thus, nutritional counseling does not have to be restricted to this moment but can be performed during the entire in-hospital period, which will also prevent the patient from being discharged before being instructed.

It is also important to note the need for better linkage between the different care levels, to guarantee the integral care of the cardiac patient. The adequate preparation of health professionals to perform the counter-referral, as well as the best quality of specialized care services to meet demand, are fundamental for a successful referral.

\section{Limitations}

Some inherent limitations deserve to be highlighted: (1) much information was self-reported, and was dependent on the interviewee's memory, which may have been influenced by some independent factors, such as level of education and clinical condition at the time of the interview. In addition, many patients were elderly, which could lead to a larger memory bias; (2) As part of the research was performed by telephone, the contact with some patients was compromised, due to difficulty in understanding, or to health problems such as hearing or mental deficiencies.

In order to reduce the limitations of the study, a pilot study was conducted prior to data collection, aiming to identify the ideal time interval for the telephone follow-up, in order to reduce memory loss, and also to standardize the interview questions, so that all patients, regardless of socioeconomic status, understood the points raised.

\section{Conclusion}

The results of this research demonstrate the lack of documentation of in-hospital nutritional counseling, as well as the low quality of this orientation given to patients with STEMI in both health services of Sergipe especially in the public service.

These data cannot only represent the reality of the state of Sergipe, but also a national situation that needs to be better investigated in order to achieve improvements in the quality of the health service as a whole in the country, mainly the quality of in-hospital nutritional status counseling. This is a low-cost action that currently is not well performed; if achieved in an equitable manner, it can be very favorable for increasing the nutritional knowledge and clinical prognosis of patients with STEMI. 


\section{Original Article}

\section{Author contributions}

Conception and design of the research: Lima TCRM, Silva DG, Oliveira JC, Oliveira LCS, Arcelino LAM, Oliveira JC, Sousa ACS, Barreto Filho JAS; Acquisition of data: Lima TCRM, Oliveira JC, Oliveira LCS, Arcelino LAM, Oliveira JC; Analysis and interpretation of the data: Lima TCRM, Silva DG, Barreto IDC, Sousa ACS, Barreto Filho JAS; Statistical analysis: Lima TCRM, Barreto IDC; Obtaining financing: Oliveira JC, Oliveira LCS, Oliveira JC, Barreto Filho JAS; Writing of the manuscript: Lima TCRM; Critical revision of the manuscript for intellectual content: Silva DG, Barreto IDC, Oliveira JC, Oliveira LCS, Arcelino LAM, Oliveira JC, Sousa ACS, Barreto Filho JAS.

\section{Potential Conflict of Interest}

No potential conflict of interest relevant to this article was reported.

\section{References}

1. World Health Organization (WHO). Global status report on noncommunicable diseases 2010. Geneva: World Health Organization; 2011 [citado 15 dez. 2018]. Disponível em: http://www.who.int/nmh/ publications/ncd_report_full_en.pdf.

2. Caluza ACV, Barbosa AH, Gonçalves I, Oliveira CA, Matos LN, Zeefried C, et al. ST-Elevation myocardial infarction network: systematization in 205 cases reduced clinical events in the public health care system. Arq Bras Cardiol. 2012;99(5):1040-8.

3. Huguenin FP, Pinheiro RS, Almeida RMVR, Catelli AF. Characterization of the variation of health care taking into account the costs of hospital admissions for acute myocardial infarction in Brazilian Unified Health System. Rev. Bras. Epidemiol. 2016;19(2):229-42.

4. Brant LCC, Nascimento BR, Passos VMA, Duncan BB, Bensenõr IJM, Malta DC, et al. Variations and particularities in cardiovascular disease mortality in Brazil and Brazilian states in 1990 and 2015: estimates from the Global Burden of Disease. Rev Bras Epidemiol. 2017;20(Suppl 1):116-28.

5. World Health Organization (WHO). Cardiovascular diseases (CVDs). Geneva: World Health Organization; 2017 [citado 15 dez. 2018]. Disponível em: http://www.who.int/cardiovascular_diseases/en/.

6. Herdy AH, López-Jiménez F, Terzic CP, Milani M, Stein R, Carvalho T, et al. Diretriz sul-americana de prevenção e reabilitação cardiovascular. Arq Bras Cardiol. 2014;103(2):1-31.

7. Urbinati S, Olivari Z, Gonzini L, Savonitto S, Farina R, Del Pinto M, et al. Secondary prevention after acute myocardial infarction: drug adherence, treatment goals, and predictors of health lifestyle habits. The BLITZ-4 Registry. Eur J Prev Cardiol. 2015;22(12):1548-56.

8. Sandesara PB, Lambert CT, Gordon NF, Fletcher GF, Franklin BA, Wenger NK, et al. Cardiac rehabilitation and risk reduction: time to "rebrand and reinvigorate". J Am Coll Cardiol. 2015;65(4):389-95.

9. Piepoli MF, Hoes AW, Agewall S, Albus C, Brotons C, Catapano AL, et al. 2016 European Guidelines on cardiovascular disease prevention in clinical practice: The Sixth Joint Task Force of the European Society of Cardiology and Other Societies on Cardiovascular Disease Prevention

\section{Sources of Funding}

This study was funded by $\mathrm{CNPq}$, chamada pública no-14/2013.

\section{Study Association}

This article is part of the thesis of master submitted by Ticiane Clair Remacre Munareto Lima, from Universidade Federal de Sergipe.

\section{Ethics approval and consent to participate}

This study was approved by the Ethics Committee of the Universidade Federal de Sergipe under the protocol number 2099.430. All the procedures in this study were in accordance with the 1975 Helsinki Declaration, updated in 2013. Informed consent was obtained from all participants included in the study. in Clinical Practice (constituted by representatives of 10 societies and by invited experts)Developed with the special contribution of the European Association for Cardiovascular Prevention \& Rehabilitation (EACPR). Eur Heart J. 2016;37(29):2315-81.

10. Falud AA, Izar MCO, Saraiva JFK, Chacra APM, Bianco HT, Afiune Neto A, et al. Atualização da Diretriz Brasileira de Dislipidemias e Prevenção da Aterosclerose - 2017. Arq Bras Cardiol. 2017;109(2 Suppl 1):1-76.

11. Lorgeril M, Salen P, Martin JL, Monjaud I, Delaye J, Mamelle N. Mediterranean diet, traditional risk factors, and the rate of cardiovascular complications after myocardial infarction final report of the lyon diet heart study. Circulation. 1999;99(6):779-85

12. Yusuf S, Hawken S, Ounpuu S, Dans T, Avezum A, Lanas F, et al. Effect of potentially modifiable risk factors associated with myocardial infarction in 52 countries (the INTERHEART study): case-control study. Lancet. 2004;364(9438):937-52.

13. Chen ST, Maruthur NM, Appel LJ. The effect of dietary patterns on estimated coronary heart disease risk results from the dietary approaches to stop hypertension (DASH) trial. Circ Cardiovasc Qual Outcomes. 2010;3(5):484-9.

14. Ros E, Martínez-González MA, Estruch R, Salas-Salvadó J, Fitó M, Martínez JA, et al. Mediterranean diet and cardiovascular helth: teachings of the PREDIMED study. Adv Nutr. 2014;5(3):330S-6S.

15. Miller V, Mente A, Dehghan M, Rangarajan S, Zhang X, Swaminathan $\mathrm{S}$, et al. Fruit, vegetable, and legume intake, and cardiovascular disease and deaths in 18 countries (PURE): a prospective cohort study. Lancet. 2017;390(10107):2037-49.

16. Task Force on the management of ST-segment elevation acute myocardial infarction of the European Society of Cardiology (ESC), Steg PG, James SK, Atar D, Badano LP, Blömstrom-Lundqvist C, et al. Task force on the management of ST-segment elevation acute myocardial infarction of the European Society of Cardiology (ESC). ESC guidelines for the management of acute myocardial infarction in patients presenting with ST-segment elevation. Eur Heart J. 2012;33(20):2569-619. 
17. RoffI M, Patrono C, Collet JP, Mueller C, Valgimigli M, Andreotti F, et al. 2015 ESC Guidelines for the management of acute coronary syndromes in patients presenting without persistent ST-segment elevation: Task Force for the Management of Acute Coronary Syndromes in Patients Presenting without PersistentST-Segment Elevation of the European Society of Cardiology (ESC). Eur Heart J. 2015;37(3):267-315.

18. Van Horn L, Carson JA, Appel LJ, Burke LE, Economos C, Karmally W, et al. Recommended Dietary Pattern to Achieve Adherence to the American Heart Association/American College of Cardiology (AHA/ACC) Guidelines: A Scientific Statement From the American Heart Association. Circulation. 2016;134(22):e505-29.

19. Sacks FM, Lichintenstein AH, Wu JHY, Appel LJ, Creager MA, Kris-Etherton PM, et al. Dietary fats and cardiovascular disease: a presidential advisory from the American Heart Association. Circulation. 2017;136(3):e1-23

20. Schiele F, Gale CP, Bonnefoy E, Capuano F, Claeys MJ, Danchin N, et al. Quality indicators for acute myocardial infarction: A position paper of the Acute Cardiovascular Care Association. Eur Heart J Acute Cardiovasc Care. 2017;6(1):34-59.

21. Ferreira GMTM, Correia LC, Reis H, Ferreira Filho CB, Freitas F, Ferreira GM, et al. Increased Mortality and Morbidity Due to Acute Myocardial Infarction in a Public Hospital, in Feira de Santana, Bahia. Arq Bras Cardiol. 2009;93(2):97-99

22. Nunes BP, Thumé E, Tomasi E, Duro SMS, Facchini LA. Socioeconomic inequalities in the access to and quality of health care services. Rev Saúde Pública. 2014;48(6):968-76

23. Instituto Brasileiro de Geografia e Estatística (IBGE). Pesquisa nacional de saúde 2013: acesso e utilização dos serviços de saúde, acidentes e violências no Brasil, grandes regiões e unidades da federação. Rio de Janeiro: IBGE; 2015

24. Piegas LS, Timerman A, Feitosa GS, Nicolau JC, Mattos LAP, Andrade MD, et al. V Diretriz da Sociedade Brasileira de Cardiologia sobre Tratamento do Infarto Agudo do Miocárdio com Supradesnível do Segmento ST. Arq Bras Cardiol. 2015;105(2 Supl 1):1-105

25. Scagliusi FB, Polacow Vo, Cordás TA, Coelho D, Alvarenga M, Philippi ST, et al. Translation, adaptation and psychometric evaluation of the National Health Interview Survey Cancer Epidemiology Nutrition Knowledge Scale. Rev Nutr. 2006;19(4):425-36.

26. Ibanez B, James S, Agewall S. Antunes MJ, Bucciarelli-Ducci C, Bueno H, et al. 2017 ESC Guidelines for the management of acute myocardial infarction in patients presenting with ST-segment elevation: The Task Force for the management of acute myocardial infarction in patients presenting with STsegment elevation of the European Society of Cardiology (ESC). Eur Heart J. 2018;39(2):119-77.

27. Xavier HT, Izar MC, Faria Neto JR, Assad M H, Rocha VZ, Sposito AC, et al. Diretriz Brasileira de Dislipidemias e Prevenção da Aterosclerose. Arq Bras Cardiol. 2013;101(4 Supl 1):1-22.
28. World Health Organization (WHO). Obesity: preventing and managing the global epidemic. Geneva: Report of a WHO consultation; 2000. (WHO Technical Report Series 894)

29. Randles RH, Wolfe DA. Introduction to the theory of nonparametric statistics, New York: Wiley; 1979.

30. Almeida PF, Giovanella L, Mendonça MHM, Escorel S. Challenges for healthcare coordination: strategies for integrating levels of care in large cities. Cad Saúde Pública. 2010;26(2):286-98.

31. Erdmann AL, Lanzoni GMM, Callegaro GD, Baggio MA, Koerich, C. Compreendendo o processo de viver significado por pacientes submetidos a cirurgia de revascularização do miocárdio. Rev Latino-Am Enferm. 2013;21(1):8 telas.

32. Cunha KS, Erdmann AL, Higashi GDC, Baggio MA, Kahl C, Koerich C, et al Myocardial revascularization: unveiling strategies in reference and counter reference in primary health care. Rev Baiana Enferm. 2016;30(1):295-304.

33. Scheffer M, Cassenote A, Guilloux AG, Miotto BA, Mainardi GM Matijasevich A, et al. Demografia médica no Brasil 2015. Departamento de Medicina Preventiva, Faculdade de Medicina da USP. Conselho Regional de Medicina do Estado de São Paulo. São Paulo: Conselho Federal de Medicina; 2015

34. Conselho Federal de Nutricionistas. Resolução CFN no 600 , de 25 de fevereiro de 2018. Dispõe sobre a definição das áreas de atuação do nutricionista e suas atribuições, indica parâmetros numéricos mínimos de referência, por área de atuação, para a efetividade dos serviços prestados à sociedade e dá outras providências. Diário Oficial da União. 23 de maio de 2018; Seção 1. p. 1-55.

35. Sialvera TE, Papadopolou A, Efstathiou SP, Trautwein EA, Ras RT, Kollia $\mathrm{N}$, et al. Structured advice provided by a dietitian increases adherence of consumers to diet and lifestyle changes and lowers blood low-density lipoprotein (LDL)-cholesterol: the increasing adherence of consumers to die \& lifestyle changes to lower (LDL) cholesterol (ACT) randomised controlled trial. J Hum Nutr Diet. 2017;31(2):197-208

36. Gomes MF, Santos RSAF, Fontbonne A et al. Orientações sobre alimentação ofertadas por profissionais da estratégia de saúde da família durante as consultas aos hipertensos e diabéticos. Rev APS. 2017;20(2):203-11.

37. Assis MM, Penna LF, Neves CM, Mendes APCC, Oliveira RM, Pereira Netto M. Avaliação do conhecimento nutricional e comportamento alimentar após educação alimentar e nutricional em adolescentes de Juiz de Fora - MG. HU Revista. 2014;40(3-4):135-43.

38. Barbosa LB, Vasconcelos SML, Correia LOS, Ferreira RC. Nutrition knowledge assessment studies in adults: a systematic review. Cien Saude Colet. 2016;21(2):449-62.

39. Aldrich L. Consumer use of information: implications for food policy Washington, DC: USDA; 1999. (Agricultural Handbook Report; 715).

40. Schneider S, Diehl K, Bock C, Herr RM, Mayer M, Görig T. Modifying health behavior to prevent cardiovascular diseases: a nationwide survey amonggerman primary care physicians. IntJ Environ Res Public Health. 2014;11(4):4218-32. 
The VICTIM register- Intra-hospital counseling

Original Article 